\title{
Podcasts and Proposals: Designing Knowledge Exchange Activities and Identifying User Referees for a Funding Application
}

\author{
By Natalie Konopinski (University of Edinburgh)
}

\begin{abstract}
What practical and ethical dilemmas do anthropologists face in the design of knowledge transfer activities for research proposals? Funding councils increasingly view knowledge exchange as an essential component of social science research. Knowledge exchange also entails the forging of reciprocal relations with informants or 'users' and the identification of non-academic 'user referees' to comment on the applicability and usefulness of the research. This paper reflects on some of the issues and concerns relating to knowledge exchange that arose during the process of writing a multi-researcher, multi-sited funding application. It addresses issues surrounding the planning of audiovisual knowledge exchange activities at the proposal stage (such as podcasts, interactive websites, photographs, and art installations), and aims to initiate discussion about the implications of Knowledge Exchange for ethnographic practice.
\end{abstract}

\section{Introduction}

Picture sitting in a university meeting room exploring the Knowledge Exchange potential of audiovisual activities as part of a large grant application. Picture listening as a multi-media professional describes the different ways to produce podcasts. $\mathrm{He}$ tells you how easy it is to create video and audio in the field, how simple it is to edit and upload them as a downloadable or live-streaming resource. Imagine describing your audiovisual ideas for an interactive website on which researchers contribute field blogs, photographs and podcasts of research-in-progress; snappy sound-bites and fieldwork footage. Podcasts that are watched and listened and responded to by informants and academics, policymakers and practitioners. Podcasts that will have 'impact'.

From time to time a university Knowledge Exchange Manager offers words of encouragement from across the table. You discuss audio equipment and editing, finances and a short documentary film. Imagine leaving the meeting filled with enthusiasm about the Knowledge Exchange (KE) potential of audiovisual activities and sitting down to email your co-applicants about it. 'Thanks for this. It all sounds great', 'This sounds great. This is extremely feasible and will look great for the proposal,' came the excited responses in my inbox.

This was just the beginning of a long grant application process for myself and three colleagues, and KE questions coloured the weeks and months of project discussions and draft proposals. Does a podcast produce KE? How do researchers ensure 
collaboration and exchange? How can anthropologists plan particular outputs before fieldwork begins?

Our application detailed a three-year research project involving three anthropologists exploring the same questions and themes in three different urban contexts. Between us we would be working with artists and musicians, community activists and urban planners, sighted and non-sighted informants. Our KE activities were designed to reflect the fields we proposed to work in, the interests and activities of our informants and the ways in which we might work with and communicate with them as well as some of the types of KE favoured by research councils. As well as planning workshops, reports and policy publications, and identifying potential partners working in policy-making and non-governmental capacities in each city, we also designed a range of audiovisual outputs aimed at facilitating collaboration and comparison within, across and beyond all three field sites. These outputs, including podcasts, a radio programme and a photographic-sonic-tactile installation, were also designed to add some all-important 'impact' potential, acting as a resource and a forum for fieldwork: a source of knowledge production as well as knowledge exchange. I was responsible for much of the information gathering for these audiovisual elements of the research and $\mathrm{KE}$, and these elements are the focus of my reflections in this paper.

The discussion here follows a few of the dilemmas faced and decisions made by our small group of anthropologists exploring the KE activities and 'impact' possibilities of audiovisual research tools. The discussion covers three themes. First, recent attention to KE among research councils. Second, the realities of designing audiovisual outputs in advance - how does one plan KE, design 'impact' and identify potential 'users'? Third, some of the ethnographic and practical issues this entails.

\section{'Excellence with Impact'}

Academics across the social sciences are now expected to demonstrate that their research has a real impact beyond the academy. Funding frameworks increasingly address not only the intellectual import but also the practical potential of academic research. Exemplified by Research Councils UK's (RCUK) recent emphasis on 'Excellence with Impact', funding councils now encourage applicants to explore the wider societal and economic applications and prospects of their work. Funding forms include an impact summary and 'pathways to impact' section, with the result that researchers must consider who might benefit from their proposed research, how they might benefit, and what they will do to engage potential 'beneficiaries' and nonacademic 'users' with and within the research. ${ }^{1}$ For us, such considerations sparked flurries of activity as we attempted to plan knowledge exchange outputs and identify potential collaborators.

RCUK describes two types of impact: academic impact 'across and within disciplines including significant advances in understanding, methods, theory and application', and economic and societal impacts, which can take the form of 'Fostering global economic performance, and specifically the economic competitiveness of the United Kingdom', 'Increasing the effectiveness of public services and policy', and

\footnotetext{
${ }^{1}$ http://impacts.rcuk.ac.uk/content/guidance.htm accessed on 16 September 2010.
} 
'Enhancing quality of life, health and output'. ${ }^{2}$ The website includes a diagram illustrating the many 'pathways' through which such impacts may be achieved.

Of course, the second, socio-economic type of impact may not apply to every academic discipline or project. As one Philosophy professor explained to Times Higher Education, 'It's all very well doing this research on an $18^{\text {th }}$ century poet, but can you do a podcast on it?' RCUK and other research councils such as the Economic and Social Research Council (ESRC) take this into account when reviewing and appraising applications. ${ }^{3}$

However, for the most part knowledge exchange is understood to involve collaboration between academics and non-academics and opening research up to a wider constituency. As such, the new funding regime and the practice of filling in grant applications is producing new categories and boundaries, and placing particular expectations upon knowledge consumers and producers. As Marilyn Strathern points out, within current evidence-based policy making regimes, knowledge transfer from academics to non-academics is built into the very notion of research (2005: 75). ${ }^{4}$ The assumption underpinning the 'excellence with impact' strategy is that knowledge must be useful to non-academics as well as academics; excellence implies both academic and socio-economic impact. Useful research, or to borrow Strathern's term, 'useful knowledge', is that which can be communicated and applied outside the academy: 'to be productive knowledge must be seen to have its 'users', that is, to be consumed by others than those who produced it (or by producers in a different capacity)' (ibid). Therefore it is not enough for researchers to produce knowledge for themselves, to produce knowledge for internal academic debate, to produce knowledge for knowledge's sake. Rather, knowledge now requires a consumer, or, in the language of knowledge exchange, a 'user' from elsewhere, in order to render it useful, relevant, productive and fund-worthy. As I discuss below, the requirement to indicate particular users of the potential research and to identify user referees can present practical and ethical questions for researchers designing a project and writing a grant proposal.

Although the 'excellence with impact' agenda and the rationale and structure produced by grant applications presupposes a distinction between consumers and producers of knowledge, the production of anthropological knowledge has always been a collaborative endeavour. Ethnography is both a process and a product of engagements, relationships and interactions with other people and with their own critical reflections and interpretations (Bomeman and Hammoudi 2009; De Neve 2006). In this way anthropologists, who spend much of their research lives working with people (usually non-academics) out in the world beyond lecture theatres and archives, are necessarily already practicing knowledge exchange all the time. Unlike some other disciplines which may encourage engaging with informants as passive

\footnotetext{
2 'What do RCUK mean by 'impact'? http://impacts.rcuk.ac.uk/content/impactmeans.htm accessed on 16 September 2010.

${ }^{3}$ Fearn, H. 2009. But can you do a podcast on it? In Times Higher Education, available at http://www.timeshighereducation.co.uk/story.asp?storycode=408453. Accessed on 16 September 2010; 'ESRC Impact, Innovation and Interdisciplinary Expectations'. Available at http://www.esrcsocietytoday.ac.uk/ESRCInfoCentre/Support/esrcexpectations/. Accessed on 27 September 2010.

${ }^{4}$ Thanks to Gemma John for her helpful comments and reading recommendation.
} 
subjects of research, anthropology's emphasis on participant observation as a method means the discipline involves informants as active collaborators in the process of knowledge production. Consequently knowledge exchange is fundamental to the methodologies and processes of anthropological and ethnographic data collection.

What is more, many anthropologists are actively engaged in applied research activities that inform public policy in the UK. My own colleagues have been variously involved in knowledge exchange - if not always called by that name - and policyrelated activities; consulting on issues of human migration and mobility for the United Nations, serving as social development advisors, working on medical research programmes with policy makers and practitioners, informing policy debates on families and children, writing reports to be used as evidence in British asylum cases and courts, advising the Scottish Executive International Development Programme, and so on. Our own project aimed to both critically address and contribute to urban planning and policy design by working both with policy makers and those affected by such policies.

As these examples highlight, anthropologists have been conducting forms of knowledge exchange long before the terms 'Knowledge Exchange' or 'Excellence with Impact' entered the funding lexicon. Both participant observation as a research method and applied anthropology as a research practice mean that when it comes to grant applications many anthropologists are well placed to identify KE practices and potential outcomes. Most anthropologists do or at least should be able to draw out potential impacts and applications of research for societal issues or public policy and to increase "public engagement with research and related societal issues ${ }^{5}$ through the production of KE materials with informants and partners.

For anthropologists, knowledge exchange is nothing new. What is new is the need to translate these long-standing research practices into the terms and categories of the current Knowledge Exchange agenda and accompanying grant application process. The implications and potential consequences of this translation are not yet entirely clear, and in these circumstances we should, at the very least, be engaging in concerted debate about the practice and application of Knowledge Exchange within the discipline.

\section{Planning Podcasts}

'Podcast, vodcast, video podcast, vidcast, all these terms refer to a downloadable media file,' the presenter on the screen tells me as I watch a podcast about podcasts on my computer. ${ }^{6} \mathrm{He}$ describes the various audio or video, or audio and video, or audio and still image forms a podcast can take, before the screen changes and I am shown a few examples of how podcasts have been used at the university. I see a polished promotional video aimed at prospective students, scientists talking about space as part of a science outreach project for schools, and a simple podcast about a farm produced using still photographs and voice-over audio.

\footnotetext{
${ }^{5} \mathrm{http}: / /$ impacts.rcuk.ac.uk/content/impactmeans.htm, accessed on 16 September 2010.

${ }^{6}$ https://www.wiki.ed.ac.uk/display/StudentInductionForum/Alex+Carter+Video, accessed on 27 September 2010.
} 
Audiovisual podcasts are not new to Anthropology. Some universities produce podcasts of lectures for students or presentations of papers by visiting speakers, the American Anthropological Association has a series of podcasts on its website aimed at members and the general public, and my own department has made a livestreaming video about studying Social Anthropology for its webpage. ${ }^{7}$ But how might podcasts be used in ethnographic research? How might podcasts produce or enhance KE? Simply uploading a podcast to a website does not ensure people will watch, take note, respond or engage.

Podcasts may be shorter and more accessible than academic texts (articles, books, reports) and therefore represent an important and useful 'pathway' to impact. Podcasts can be downloaded onto computers, laptops or portable media devices such as iPods, watched and listened to later on or while on the move. Of course, you have to interest and involve people in your website for them to access the podcasts to begin with - no hits, no knowledge exchange. So successful KE requires researchers to collaborate with partner organisations and communicate with target audiences or users to ensure media resources and web-based KE are watched or listened to and well known.

We intended to use podcasts as an ethnographic method as well as a KE technique. Each researcher would film and capture parts of their fieldwork in progress: short snappy segments of film that could be watched, engaged with and responded to via the project website. These could be anything from filming a walk through the city streets to a conversation or a particular event. At times the podcasts may even be video clips filmed by our informants. The aim was to use such audiovisual methods as a way of engaging and communicating with informants, researchers and collaborators throughout the project process. They would form an audiovisual accompaniment to fieldnotes and fieldwork. Podcasts would also enable us to communicate ideas, experiences, contexts and events with one another across our various field sites. Individuals would be able to watch and listen to the podcasts, post their own comments, spark online discussion and critique. Although our podcasts would be part of a whole audiovisual and even virtual realm of data collection and dissemination, the major research outputs would also be in the more familiar form of written articles, monographs and policy papers. Podcasts were thus included as a medium for discussion, the dissemination of ideas and findings, knowledge exchange and knowledge production.

In fact the line between ethnographic method and knowledge exchange is rather difficult to draw here. Such activities as disseminating ideas and showing fieldwork in action using podcasts and website discussion tap into new forms of contemporary ethnography. Consequently we can think of the new funding regime's focus on KE as having an impact on our ideas of ethnography and the ethnographer, both in terms of a movement away from ethnography as purely written process and product towards more visual ethnography, and in terms of expanding the scope for exploring new kinds of virtual and participatory ethnography. ${ }^{8}$ Podcasts, for instance, offer new forms of ethnographic voice and collaboration with our interlocutors. Here the

\footnotetext{
${ }^{7}$ For example ,UC Berkeley podcasts are available at http://webcast.berkeley.edu/. The AAA podcast series is available at http://webcast.berkeley.edu/ and Edinburgh's Social Anthropology video is available at http://www.san.ed.ac.uk/video.

${ }^{8}$ See for example, C. Hine. 2000. Virtual Ethnography. London: Sage; S. Pink. 2001. Doing Visual Ethnography: Images, Media and Representation in Research. London: Sage.
} 
ethnographer may not only write but also film, edit and upload aspects of fieldwork as it is taking place.

The strength or advantages of using podcasts as research tools lie in the ease with which they can be produced and accessed. One does not have to be particularly media-savvy to watch or to create such audiovisual materials. The potential weakness podcasts might offer to research and to grant proposals is that, as noted above, they only enable and enhance knowledge exchange if people watch, listen and engage with them. Furthermore podcasts also represent a particular developed world bias towards these kinds of new technologies when it comes to knowledge exchange outputs. In our case such new technologies or audiovisual KE activities were a good fit with the kinds of urban field sites we would be working in and with the informants we would be working with. What if the ethnographer is conducting fieldwork and trying to disseminate findings to people and places where there is no access to electricity, computers or the internet? The relevance and possible impacts of podcasts and other audiovisual activities as forms of $\mathrm{KE}$ are highly dependent on the context and location of research.

\section{'User referees are really important' ${ }^{\prime}$}

The research council application we were writing required references from the anticipated users of the research. Finding non-academic 'users' who can speak to the uses and relevance of research beyond the ivory tower is not necessarily an easy task. Potential partners need to be identified and included in development and design of an application. For anthropologists, more used to developing relationships with informants and interlocutors once in the field, this can mean the sometimes tricky task of establishing partnerships in advance of any actual research. For researchers with long-standing relations with a particular place and people, such connections often already exist. For me, having just completed my $\mathrm{PhD}$, this was not the case. Although I would be returning to the same field site city that I had worked in during my PhD fieldwork, the kinds of spaces and places and focus of research would be very different. During my doctoral research, contacts and access had been built up gradually as part of the fieldwork itself, evolving as I set about my ethnographic work. Such relations could not be established with a phone call or email exchange but were built on proximity and face to face conversation.

I now found myself asking friends and informants for possible contacts, searching the websites of organisations and individuals who might make a 'user referee'. I made contact with a photographer working on some interesting audiovisual projects with teenagers in the field. We exchanged emails and made tentative plans to meet when we would both be in the same city. But incompatible schedules and real world commitments soon got in the way. There was simply not time to discuss potential projects when current projects required attention. It is not always easy to engender trust and engage in relations when one is not actually doing research but only planning 'pathways' and predicting 'impact'. In the end our user references would come from elsewhere.

\footnotetext{
${ }^{9}$ Personal communication from an academic colleague on the project 02.04.2010.
} 
The user referee we worked with for the final proposal is both an academic and a community organiser involved with local politics and policy. Such individuals blur the boundaries such grant applications set up between academics and practitioners and between producers and users of research. While KE discourses demand such divisions, this boundary-making and -marking often appears quite arbitrary. An ethnographer may be both a researcher and a 'user'; a so-called 'user' may also be an academic researcher. In this way the expectations, structures and demands of grant applications themselves emerge as interesting ethnographic objects, as potential subjects of anthropological research.

Becoming a 'user referee' can also be an intimidating prospect. The role requires a person who perceives themselves as a professional or expert in their area, i.e. as qualified and equipped to pass judgement on a particular proposal. It also calls for a person familiar or at ease with the bureaucratic procedures of proposal documents, able to write for and work with these forms of paperwork and appraisal (Riles 2006). Not all collaborators, partners and users - those best placed to apprehend and assess impact potential - will also be those most comfortable or competent with the bureaucratic demands of the online application process. Therefore, the very concept of the user referee tends to favour research in which the proposed users are professionals, experts or individuals who possess the bureaucratic knowledge, technical capabilities and socio-cultural capital to navigate the application process. Other individuals are largely excluded from the possibility of becoming user referees. A referee may therefore be more likely to be a professional or expert working with or on a particular people or issues and not necessarily the immediate participants and users of research.

What is more, the identification and inclusion of user referees produces other practical and ethical challenges for the proposal-writing anthropologist. User referees are named, identified and recorded on a project proposal; a far cry from the anonymity usually afforded our informants and interlocutors. In some contexts the naming of user referees may have profound social, political and safety implications for the individuals involved. Such concerns present further implications for ways in which researchers include, identify and present referees within a research proposal.

Finally, inviting and naming a particular individual or individuals as a user referee may also be perceived by other users as providing one person with authority and influence over others. This may in turn affect the collaborations and working relationships that are crucial to a project's success.

The possible ramifications and practical challenges of choosing user referees are not confined to anthropology, but the particular nature of anthropological research demands careful consideration of who a potential 'user referee' may be and how the selection of user referees may impact on the course of the project.

\section{New media maybes and planning potentialities}

Another of our audiovisual KE plans revolved around a photographic, sonic and tactile installation using images, sounds and materials from the field. But as I sat down in the hi-tech surroundings of a university new media technology centre and began to discuss details with one of its managers, all attempts to pin down a plan 
dissolved into probability and potential. Of course we could collaborate and create an installation with visual and sound projection. Of course we could promote public engagement and public events, bringing people in to experience and take part in the exhibition. Of course we could not predict what the installation might be or how we might do it because we have do not have the ethnographic, audiovisual and tactile materials at this stage. Nor, as the manager pointed out, do we know which new media technologies may be at our disposal or on the market in three or four years time. We could only talk of a potential installation involving probable materials from a possible research project. Perhaps we should meet in the future, he suggested. When we know what we have to work with.

As this new media meeting illustrates, 'pathways to impact' means just that. One cannot predict impact but only suggest potential activities, probable beneficiaries and possible knowledge exchange. At the proposal stage, research lies in the realm of anticipation and possibility. Research proposals require applicants to consider and map out possibilities and potentialities, not concrete designs. The focus is on form not content, 'robust strategies' rather than definitive structures, 'pathways' towards impact rather than the finished KE product. ${ }^{10}$

\section{Conclusion}

Anthropologists are hardly unaware of the content of the idea of knowledge exchange, embedded as it is within the core of their practice in academic and applied research. What the formulation of KE plans and filling in of impact summaries changes is the way in which we think through and respond to the content of this idea. Faced with the $\mathrm{KE}$ agenda, the difference between anthropology and other disciplines is that our beneficiaries will often also be research participants - facilitating the collaborative production of knowledge itself. In this context KE is not simply a case of academics passing on or transferring their research to practitioners or so-called public 'users', but points to collaboration and the co-production of knowledge from the very start. What the impact agenda prompts us to do is to consider, include and expand the collaborative aspects of our work in the very planning of proposed research. If anthropology wants to both compete in the current research funding market and understand how this market may be influencing research practice then we need to produce valuable and timely responses to the call for 'Excellence with Impact'.

The kinds of knowledge exchange envisioned by research councils' impact missions speak to and expand on practical and collaborative aspects of work which most anthropologists already do. As academics fully engaged with and immersed within particular social worlds we are well placed to excel at certain kinds of knowledge exchange and societal contributions, from everyday interactions in the field to the collaborative production of textual, audiovisual and creative outputs. But doing it well will require considerable thought and debate about the implications for the discipline, the practice and the products of ethnographic research.

\footnotetext{
10 'ESRC Impact, Innovation and Interdisciplinary Expectations'. Available at http://www.esrcsocietytoday.ac.uk/ESRCInfoCentre/Support/esrcexpectations/. Accessed on 27 September 2010.
} 


\section{Postscript}

Although the Knowledge Exchange sections were well received by the research council, our funding application was not successful. The team is currently discussing ways to take the proposal forward by other means.

\section{About the author}

Natalie Konopinski received her PhD in Social Anthropology from the University of Edinburgh where she teaches ethnographic theory and methods. Her principal research interest is on the normalization of security practices, suspicion, boredom and fear in Tel Aviv, Israel.

\section{Bibliography}

Borneman, J. and Hammoudi, A. (2009), 'The Fieldwork Encounter, Experience and the Making of Truth: An Introduction', in J. Borneman and A. Hammoudi (eds), Being There: The Fieldwork Encounter and the Making of Truth, Berkeley: University of California Press.

Carter, A. (2010), Alex Carter Video 'What is a Podcast?', E-Communications Forum, The University of Edinburgh. (Available online at https://www.wiki.ed.ac.uk/display/StudentInductionForum/Alex+Carter+Video, accessed 27 September 2010).

De Neve, G. (2006), 'Hidden Reflexivity: Assistants, Informants and the Creation of Anthropological Knowledge', in G. De Neve and M. Unnithan-Kumar (eds), Critical Journeys: The Making of Anthropologists, Aldershot: Ashgate.

Economic and Social Research Council. Impact, Innovation and Interdisciplinary Expectations. (Available online at http://www.esrcsocietytoday.ac.uk/ESRCInfoCentre/Support/esrcexpectations/, accessed 27 September 2010).

Fearn, H. (2009), 'But can you do a podcast on it?', Times Higher Education. (Available online at http://www.timeshighereducation.co.uk/story.asp?storycode $=408453$, accessed 16 September 2010).

Hine, C. (2000), Virtual Ethnography, London: Sage.

Pink, S. (2001), Doing Visual Ethnography: Images, Media and Representation in Research, London: Sage.

Research Councils UK, Pathways to Impact, Online. (Available online at http://impacts.rcuk.ac.uk/content/guidance.htm, accessed 16 September 2010).

Research Councils UK, What do RCUK mean by 'impact'? (Available online at http://impacts.rcuk.ac.uk/content/impactmeans.htm, accessed 16 September 2010). 
Riles, A. (2006), Documents: Artifacts of Modern Knowledge, Ann Arbor, MI:

University of Michigan Press.

Strathern, M. (2005), 'Useful Knowledge', Proceedings of the British Academy 2005 Lectures, 139: 73-109. 